Original scientific paper

\title{
ADAPTIVE NEURO-FUZZY COMPUTING TECHNIQUE FOR PRECIPITATION ESTIMATION
}

\author{
UDC 911.2:556
}

\section{Dalibor Petković $^{1}$, Milan Gocić ${ }^{2}$, Shahaboddin Shamshirband ${ }^{3}$}

${ }^{1}$ University of Niš, Faculty of Mechanical Engineering, Serbia

${ }^{2}$ University of Niš, Faculty of Civil Engineering and Architecture, Serbia

${ }^{3}$ University of Malaya, Faculty of Computer Science and Information Technology, Malaysia

\begin{abstract}
The paper investigates the accuracy of an adaptive neuro-fuzzy computing technique in precipitation estimation. The monthly precipitation data from 29 synoptic stations in Serbia during 1946-2012 are used as case studies. Even though a number of mathematical functions have been proposed for modeling the precipitation estimation, these models still suffer from the disadvantages such as their being very demanding in terms of calculation time. Artificial neural network (ANN) can be used as an alternative to the analytical approach since it offers advantages such as no required knowledge of internal system parameters, compact solution for multi-variable problems and fast calculation. Due to its being a crucial problem, this paper presents a process constructed so as to simulate precipitation with an adaptive neuro-fuzzy inference (ANFIS) method. ANFIS is a specific type of the ANN family and shows very good learning and prediction capabilities, which makes it an efficient tool for dealing with encountered uncertainties in any system such as precipitation. Neural network in ANFIS adjusts parameters of membership function in the fuzzy logic of the fuzzy inference system (FIS). This intelligent algorithm is implemented using Matlab/Simulink and the performances are investigated. The simulation results presented in this paper show the effectiveness of the developed method.
\end{abstract}

Key Words: Precipitation, Adaptive Neuro-fuzzy System (ANFIS), Estimation

\section{INTRODUCTION}

Accurate estimation of precipitation is important for hydrologic and ecological modeling [1]. Several studies on the estimation of precipitation have been carried out in the last few years. Polarimetric rate estimation techniques such as ZPHI [2] and ZZDR

Received October 16, 2015 / Accepted January 31, 2016

Corresponding author: Dalibor Petković

Faculty of Mechanical Engineering, Aleksandra Medvedeva 14, 18000 Niš, Serbia

E-mail: dalibortc@gmail.com 
[3] can be used for quantitative precipitation estimation. In addition, remotely sensed precipitation from radar and satellites can improve precipitation estimates [4-8].

Quantitative precipitation estimation provides information of practical importance which can be applied to different fields such as water resources management, agricultural production, planning biodiversity, and flood protection. The precipitation estimation is one of the key elements in an assessment of the global climate change that represents a nonlinear and discontinuous process [9].

In recent years, various artificial intelligence methods have been developed for the estimation of precipitation [10-13]. Artificial neural network (ANN) offers a promising alternative for finding precipitation characteristics as well as learning complex nonlinear relationships. For example, Zhang et al. [9] applied artificial neural network group techniques for precipitation estimation in which average errors for the overall precipitation event fall below $10 \%$. Grimes et al. [14] proposed ANN with a principal component analysis to precipitation estimation on a daily timescale. Freiwan and Cigizoglu [15] developed ANN models that were trained with the method of back-propagation algorithm to predict precipitation for the next month. Chiang et al. [16] took into account the dynamic ANN to construct quantitative precipitation estimation by using a three-dimensional radar data structure. Nkuna and Odiyo [17] and Mwale et al. [18] estimated missing precipitation data by using the ANN models. Nastos et al. [19] developed the ANN models for the prediction of the precipitation intensity for the next four months. In general, all of the cited studies have reported an improvement in performance by using ANNs.

Even though a number of models have been proposed for modeling the precipitation, they are still suffering from the disadvantages such as their being very demanding in terms of calculation time. ANN can be used as an alternative to the analytical approach since it offers advantages such as no required knowledge of internal system parameters, compact solution for multi-variable problems and fact calculation.

In this investigation adaptive neuro-fuzzy inference system (ANFIS) [20], which is a specific type of the ANN family, was used to estimate precipitation. For the presently developed neural network, monthly precipitation data from 29 synoptic stations in Serbia during 1946-2012 were used as case studies i.e. as ANFIS training data. The main purpose of this study is to analyze the performances of ANFIS for monthly precipitation estimation.

ANFIS shows very good learning and prediction capabilities, which makes it an efficient tool for dealing with encountered uncertainties in any system. Researchers used ANFIS as a hybrid intelligent system that enhances the ability to automatically learn and adapt in various engineering systems [21-26]. So far, there are many studies of the application of ANFIS for estimation and real-time identification of many different systems [27-35].

\section{STUdy AREA AND COLLECTEd DATA}

The study area was Serbia, which is located in the central part of the Balkan Peninsula. Northern Serbia is mainly flat, while its central and southern areas consist of hilly and mountainous. The climate of the country is temperate continental, with a gradual transition between the four seasons of the year. 
Series of monthly precipitation data were chosen from 29 synoptic stations (Fig. 1) for the period of 1946-2012. The geographical characteristics, mean and standard deviation of annual precipitation time series of the observed stations are listed in Table 1.

Table 1 Geographical description, mean and standard deviation of annual precipitation time series of the synoptic stations used in the study

\begin{tabular}{|c|c|c|c|c|c|}
\hline Station name & $\begin{array}{l}\text { Longitude } \\
\text { (E) }\end{array}$ & $\begin{array}{l}\text { Latitude } \\
\text { (N) }\end{array}$ & $\begin{array}{c}\text { Elevation } \\
\text { (m a.s.1.) }\end{array}$ & $\begin{array}{l}\text { Mean } \\
(\mathrm{mm})\end{array}$ & $\begin{array}{c}\text { Standard } \\
\text { deviation } \\
(\mathrm{mm})\end{array}$ \\
\hline 1. Banatski Karlovac & $20^{\circ} 48^{\prime}$ & $45^{\circ} 03^{\prime}$ & 89 & 627.0 & 139.4 \\
\hline 2. Becej & $20^{\circ} 04^{\prime}$ & $45^{\circ} 37^{\prime}$ & 78 & 579.7 & 130.8 \\
\hline 3. Belgrade & $20^{\circ} 28^{\prime}$ & $44^{\circ} 48^{\prime}$ & 132 & 692.1 & 132.5 \\
\hline 4. Crni Vrh & $21^{\circ} 58^{\prime}$ & $44^{\circ} 08^{\prime}$ & 1027 & 789.9 & 154.9 \\
\hline 5. Cuprija & $21^{\circ} 22^{\prime}$ & $43^{\circ} 56^{\prime}$ & 123 & 651.8 & 124.2 \\
\hline 6. Dimitrovgrad & $22^{\circ} 45^{\prime}$ & $43^{\circ} 01^{\prime}$ & 450 & 631.0 & 118.0 \\
\hline 7. Kikinda & $20^{\circ} 28^{\prime}$ & $45^{\circ} 51^{\prime}$ & 81 & 549.7 & 123.8 \\
\hline 8. Kopaonik & $20^{\circ} 48^{\prime}$ & $43^{\circ} 17^{\prime}$ & 1711 & 727.3 & 217.6 \\
\hline 9. Kragujevac & $20^{\circ} 56^{\prime}$ & $44^{\circ} 02^{\prime}$ & 185 & 628.6 & 112.2 \\
\hline 10. Kraljevo & $20^{\circ} 42^{\prime}$ & $43^{\circ} 43^{\prime}$ & 215 & 748.1 & 132.7 \\
\hline 11. Krusevac & $21^{\circ} 21^{\prime}$ & $43^{\circ} 34^{\prime}$ & 166 & 643.6 & 134.3 \\
\hline 12. Kursumlija & $21^{\circ} 16^{\prime}$ & $43^{\circ} 08^{\prime}$ & 383 & 635.4 & 131.7 \\
\hline 13. Leskovac & $21^{\circ} 57^{\prime}$ & $42^{\circ} 59^{\prime}$ & 230 & 614.6 & 109.3 \\
\hline 14. Loznica & $19^{\circ} 14^{\prime}$ & $44^{\circ} 33^{\prime}$ & 121 & 820.0 & 140.7 \\
\hline 15. Negotin & $22^{\circ} 33^{\prime}$ & $44^{\circ} 14^{\prime}$ & 42 & 637.5 & 132.7 \\
\hline 16. Nis & $21^{\circ} 54^{\prime}$ & $43^{\circ} 20^{\prime}$ & 204 & 578.8 & 110.5 \\
\hline 17. Novi Sad & $19^{\circ} 51^{\prime}$ & $45^{\circ} 20^{\prime}$ & 86 & 613.8 & 153.8 \\
\hline 18. Palic & $19^{\circ} 46^{\prime}$ & $46^{\circ} 06^{\prime}$ & 102 & 550.1 & 117.8 \\
\hline 19. Pozega & $20^{\circ} 02^{\prime}$ & $43^{\circ} 50^{\prime}$ & 310 & 746.7 & 134.2 \\
\hline 20. Sjenica & $20^{\circ} 01^{\prime}$ & $43^{\circ} 16^{\prime}$ & 1038 & 718.7 & 130.7 \\
\hline 21. Sombor & $19^{\circ} 05^{\prime}$ & $45^{\circ} 47^{\prime}$ & 87 & 588.2 & 129.1 \\
\hline 22. Smederevska Palanka & $20^{\circ} 57^{\prime}$ & $44^{\circ} 22^{\prime}$ & 121 & 635.7 & 115.7 \\
\hline 23. Sremska Mitrovica & $19^{\circ} 38^{\prime}$ & $44^{\circ} 58^{\prime}$ & 82 & 621.9 & 122.3 \\
\hline 24. Valjevo & $19^{\circ} 55^{\prime}$ & $44^{\circ} 17^{\prime}$ & 176 & 775.9 & 134.3 \\
\hline 25. Veliko Gradiste & $21^{\circ} 31^{\prime}$ & $44^{\circ} 45^{\prime}$ & 80 & 666.5 & 140.3 \\
\hline 26. Vranje & $21^{\circ} 55^{\prime}$ & $42^{\circ} 33^{\prime}$ & 432 & 601.5 & 114.5 \\
\hline 27. Zajecar & $22^{\circ} 17^{\prime}$ & $43^{\circ} 53^{\prime}$ & 144 & 603.2 & 116.1 \\
\hline 28. Zlatibor & $19^{\circ} 43^{\prime}$ & $43^{\circ} 44^{\prime}$ & 1028 & 954.9 & 151.9 \\
\hline 29. Zrenjanin & $20^{\circ} 21^{\prime}$ & $45^{\circ} 24^{\prime}$ & 80 & 576.4 & 121.0 \\
\hline
\end{tabular}

The mean annual precipitation varied between $549.7 \mathrm{~mm}$ to $954.9 \mathrm{~mm}$. Dry areas with precipitation below $600 \mathrm{~mm}$ is in the northeast (Becej, Kikinda, Palic, Sombor, Zrenjanin). The area along the valley of the South Morava to Vranje has the precipitation to $650 \mathrm{~mm}$ during the year. A larger and more compact area to the west and southwest is the wettest region of Serbia. In the mountains, such as Mt. Zlatibor and Mt. Kopaonik, precipitation may rise up to $1000 \mathrm{~mm}$ per year. The detailed analysis of the considered time series is presented in [36-38]. 


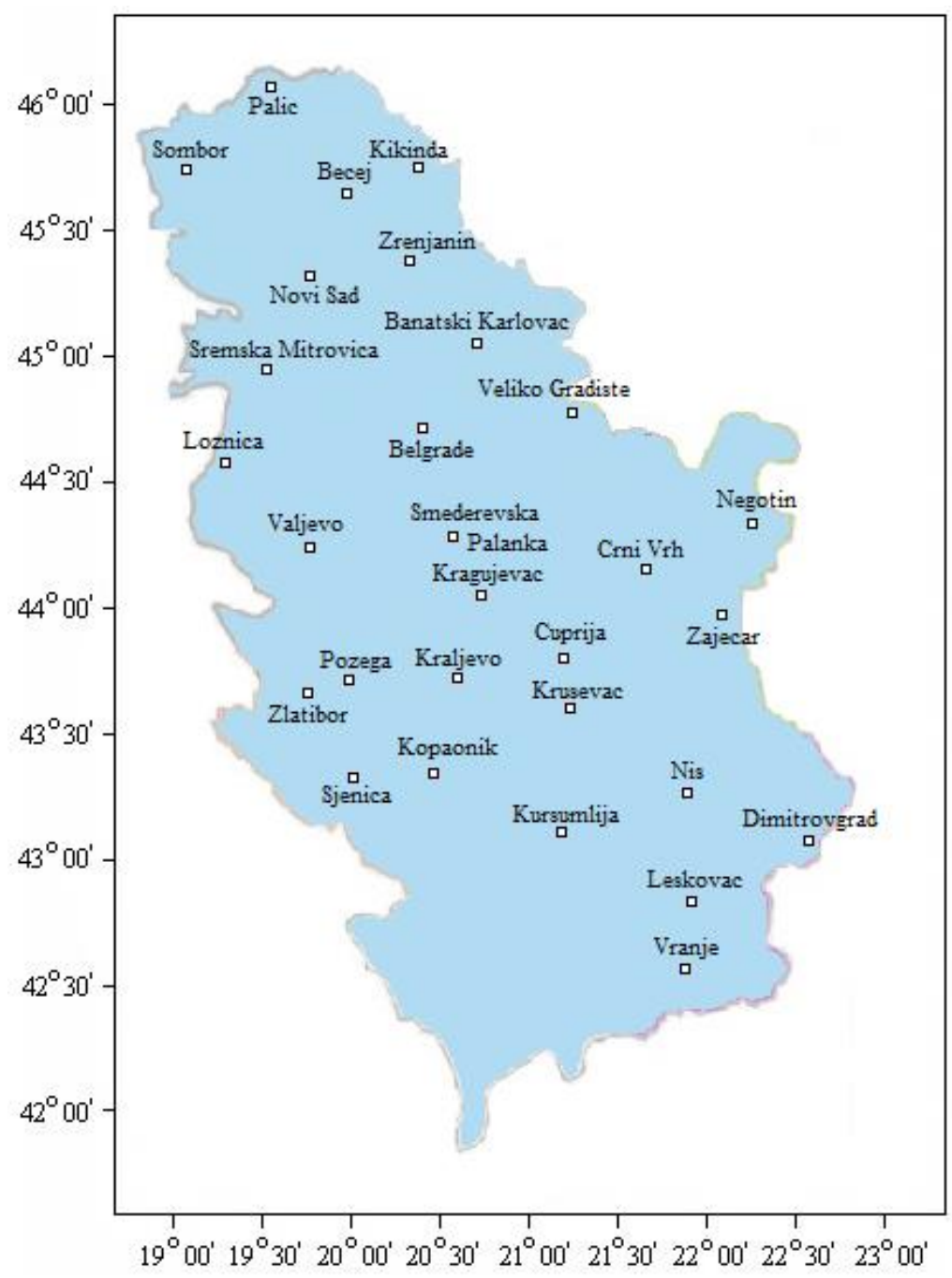

Fig. 1 Spatial distribution of the 29 synoptic stations in Serbia map

Data were obtained from the Republic Hydrometeorological Service of Serbia (http://www.hidmet.gov.rs/), that carried out technical and quality control of these measurements. There are no missing values in the data set. Besides, the homogeneity test and the Kendall autocorrelation analysis [39] were applied to the monthly precipitation time series of each station. 


\section{ADAPTIVE NEURO-FUZZY APPLICATION}

Fuzzy Inference System (FIS) is the main core of ANFIS. It is based on expertise expressed in terms of 'IF-THEN' rules and can thus be employed to predict the behavior of many uncertain systems. FIS advantage is that it does not require knowledge of the underlying physical process as a precondition for its application. Thus, ANFIS integrates the fuzzy inference system with a back-propagation learning algorithm of neural network. The basic structure of a FIS consists of three conceptual components: a rule base, which contains a selection of fuzzy rules; a database, which defines the membership functions (MFs) used in the fuzzy rules; and a reasoning mechanism, which performs the inference procedure upon the rules and the given facts to derive a reasonable output or conclusion. These intelligent systems combine knowledge, technique and methodologies from various sources. They possess human-like expertise within a specific domain - adapt themselves and learn to do better in changing environments. In ANFIS, neural networks recognize patterns, and help adaptation to environments. ANFIS is tuned with a back propagation algorithm based on the collection of input-output data.

ANFIS model will be established in this study to estimate participation in Serbia according to the monthly precipitation data during 1946-2012. The ANFIS networks should determine the optimal participation for a given number of data inputs. Fuzzy logic toolbox in MATLAB was used for the entire process of training and evaluation of fuzzy inference system. Fig. 2 shows an ANFIS structure with one input, month in year, $x$.

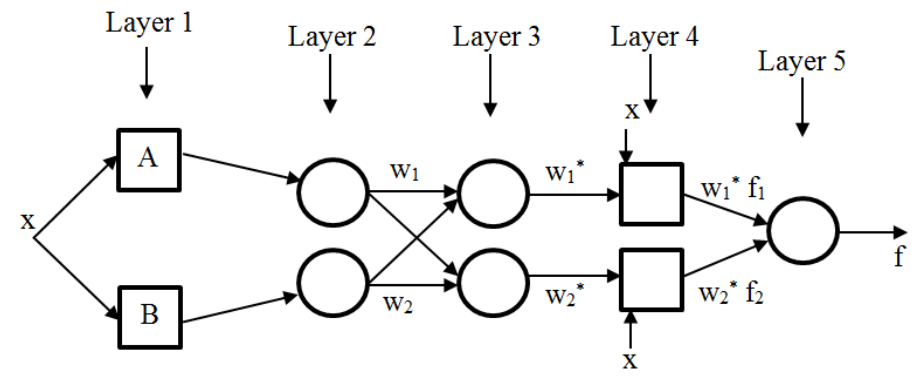

Fig. 2 ANFIS structure

In this work, the first-order Sugeno model with two inputs and fuzzy IF-THEN rules of Takagi and Sugeno's type is used.

The first layer consists of input variables membership functions (MFs). This layer just supplies the input values to the next layer. The input is month in year.

In this study, bell-shaped MFs (2) with maximum equal to 1 and minimum equal to 0 are chosen.

The second layer (membership layer) checks for the weights of each MFs. It receives the input values from the 1st layer and acts as MFs to represent the fuzzy sets of the respective input variables. Every node in the second layer is non-adaptive and this layer multiplies the incoming signals and sends the product out. Each node output represents the firing strength of a rule or weight.

The third layer is called the rule layer. Each node (each neuron) in this layer performs the pre-condition matching of the fuzzy rules, i.e. they compute the activation level of each rule, the number of layers being equal to the number of fuzzy rules. Each node of 
these layers calculates the weights, which are normalized. The third layer is also nonadaptive and every node calculates the ratio of the rule's firing strength to the sum of all the rules' firing strengths. The outputs of this layer are called normalized firing strengths or normalized weights.

The fourth layer is called the defuzzification layer and it provides the output values resulting from the inference of rules. Every node in the fourth layer is an adaptive node with node function.

The fifth layer is called the output layer which sums up all the inputs coming from the fourth layer and transforms the fuzzy classification results into a crisp (binary). The output represents an estimated modulation transfer function of the optical system. The single node in the fifth layer is not adaptive and this node computes the overall output as the summation of all the incoming signals.

The hybrid learning algorithms were applied to identify the parameters in the ANFIS architectures. In the forward pass of the hybrid learning algorithm, functional signals go forward till Layer 4 and the consequent parameters are identified by the least squares estimate. In the backward pass, the error rates propagate backwards and the premise parameters are updated by the gradient descent.

\section{ANFIS RESULTS}

At the beginning, the ANFIS network was trained with measured data by above presented experimental procedure. The training data are presented in Fig. 3 for one station (Becej). The ANFIS network determines optimal precipitation based on the measured data.

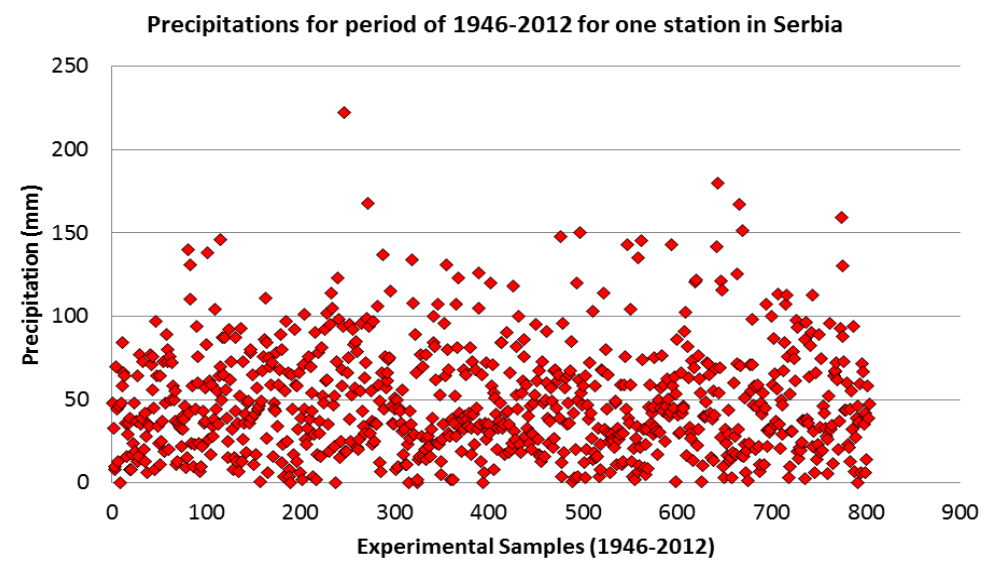

Fig. 3 Experimental data for ANFIS training for one station (Becej)

Three bell-shaped membership functions were used to fuzzify the ANFIS input. After training process the ANFIS networks were tested. Fig. 5 shows the result of the testing of ANFIS network for three distinct regions in Serbia. These regions were experimentally determined in $[37,38]$. Here, two stations are chosen to represent one region as shown in Figs. 4-6. 
Region-1

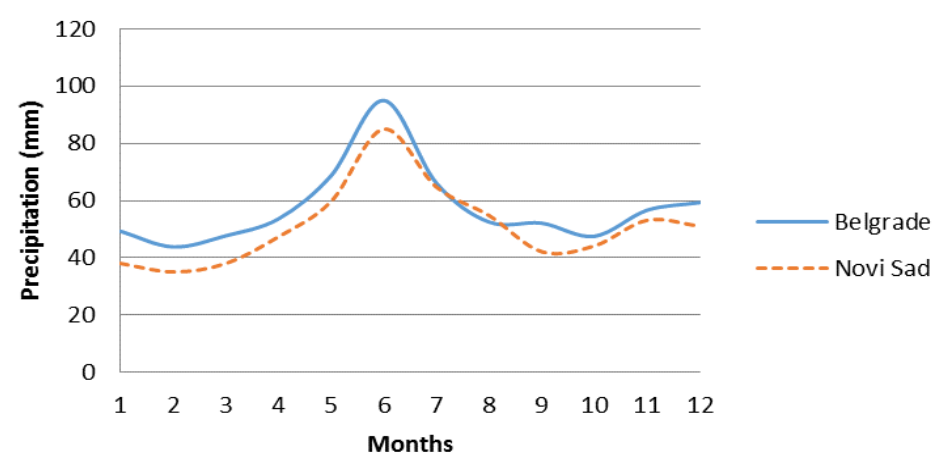

Fig. 4 ANFIS predicted results of the precipitation in Serbia for region 1

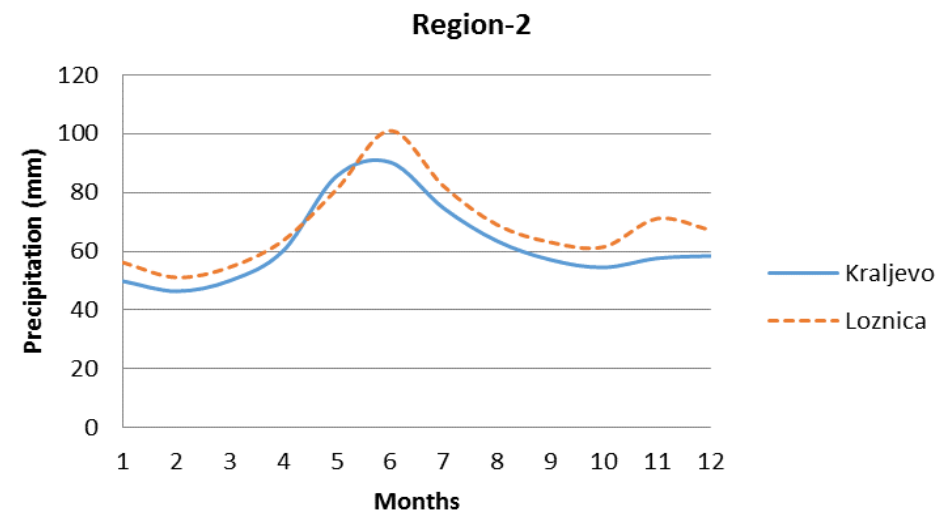

Fig. 5 ANFIS predicted results of the precipitation in Serbia for region 2

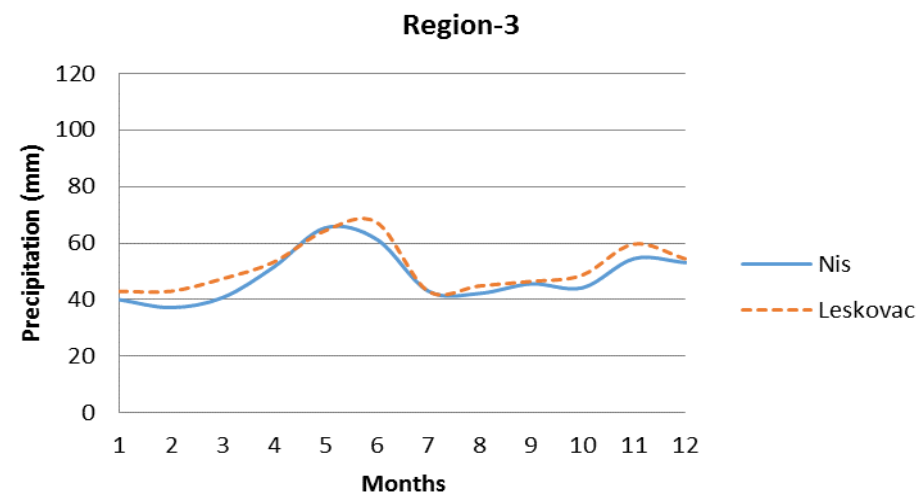

Fig. 6 ANFIS predicted results of the precipitation in Serbia for region 3 
Finally, we performed precipitation prediction for Serbia based on the regions precipitations as shown in Fig. 6. The red solid line represents ANFIS prediction of the Serbia participation while the estimated precipitations at all the stations are also depicted in Fig. 7.

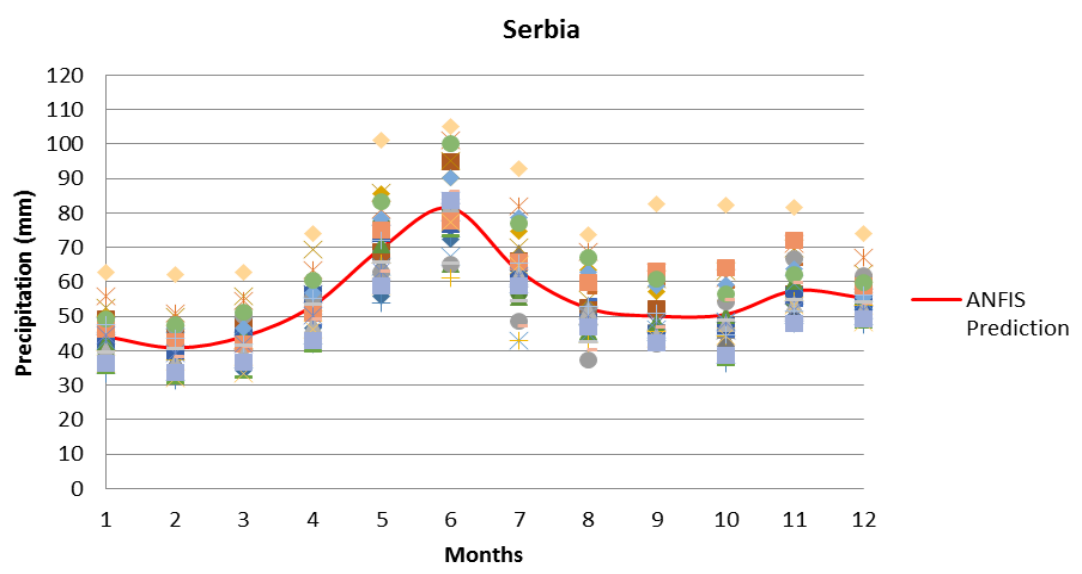

Fig. 7 ANFIS predicted results of the precipitation in Serbia

The obtained results show that the maximum precipitation is in June. The decreasing trend of precipitation is detected in the summer, which is in an agreement with the results reported in [40].

\section{CONCLUSION}

The precipitation was investigated by ANFIS methodology in Serbia using monthly precipitation time series from 29 stations during the period of 1948-2012. The ANFIS method has been presented and tested for developing an alternative method to estimate precipitation. The main advantage of the soft computing scheme has very good learning and prediction capabilities, which makes it an efficient tool for dealing with encountered uncertainties in any system such as precipitation. Since there are three distinct regions in Serbia with respect to the precipitation $[37,38]$, we estimated precipitation for these regions. Afterwards the ANFIS was applied to predict overall estimation according to all the stations in Serbia from period 1948-2012.

Simulations were run in MATLAB and the results were observed on the corresponding output blocks. The main advantages of the ANFIS scheme are: it is computationally efficient, well-adaptable with optimization and adaptive techniques. The developed strategy is not only simple but also reliable and may be easy to implement in real time applications using some interfacing cards like the dSPACE, data acquisition cards, NI cards, etc. for the control of various parameters. This can also be combined with expert systems and rough sets for other applications. ANFIS can also be used with systems handling more complex parameters. Another advantage of ANFIS is its speed of operation; the tedious task of training membership functions is done in ANFIS. 


\section{REFERENCES}

1. Fodor, N., Kovács, G.J., 2005, Sensitivity of crop models to the inaccuracy of meteorological observations, Physics and Chemistry of the Earth, 30(1), pp. 53-57.

2. Testud, J., Le Bouar, E., Obligis, E., Ali-Mehenni, M., 2000, The rain profiling algorithm applied to polarimetric weather radar, Journal of Atmospheric and Oceanic Technology, 17(1), pp. 332-356.

3. Illingworth, A.J., Thompson, R.J., 2005, The estimation of moderate rain rates with operational polarisation radar, In: 32nd Int. Conf. on Radar Meteorology, Albuquerque, Paper P9R.1, Am. Meteorol. Soc.

4. Clark, M.P., Slater, A.G., 2006, Probabilistic quantitative precipitation estimation in complex terrain, Journal of Hydrometeorology, 7(1), pp. 13-22.

5. Crochet, P., 2009, Enhancing radar estimates of precipitation over complex terrain using information derived from an orographic precipitation model, Journal of Hydrology, 377(1), pp. 417-433.

6. Katiraie-Boroujerdya, P.-S., Nasrollahi, N., Hsu, K.-L., Sorooshian, S., 2013, Evaluation of satellitebased precipitation estimation over Iran, Journal of Arid Environments, 97(1), pp. 205-219.

7. Zhang, X., Srinivasan, R., 2010, GIS-based spatial precipitation estimation using next generation radar and raingauge data, Environmental Modelling and Software, 25(12), pp. 1781-1788.

8. Dai, Q., Han, D., Rico-Ramirez, M., Srivastava, P. K., 2014, Multivariate distributed ensemble generator: A new scheme for ensemble radar precipitation estimation over temperate maritime climate, Journal of Hydrology, 511(1), pp. 17-27.

9. Zhang, M., Fulcher, J., Scofield, R. A., 1997, Rainfall estimation using artificial neural network group, Neurocomputing 16(2), pp. 97-115.

10. Vahid, N., Ahmad, T., Peyman, A., Jamal, S., Esmaeil, H., 2014, A new hybrid algorithm for rainfallrunoff process modeling based on the wavelet transform and genetic fuzzy system, Journal of Hydroinformatics, 26(5), pp. 1004-1024.

11. Wen-chuan, W., Dong-mei, X., Kwok-wing, C., Shouyu., 2013, Improved annual rainfall-runoff forecasting using PSO-SVM model based on EEMD, Journal of Hydroinformatics, 15(4), pp. 1377-1390

12. Vahid, N., Masoumeh, P., 2013, Conjunction of SOM-based feature extraction method and hybrid wavelet-ANN approach for rainfall-runoff modeling, Journal of Hydroinformatics, 15(3), pp. 829-848.

13. Rodríguez-Vázquez, K., Arganis-Juárez, M. L., Cruickshank-Villanueva, C., Domínguez-Mora, R. 2011, Rainfall-runoff modelling using genetic programming, Journal of Hydroinformatics, 14(1), pp. 108-121.

14. Grimes, D.I.F., Coppola, E., Verdecchia, M., Visconti, G., 2003, A neural network approach to real-time rainfall estimation for Africa using satellite data, Journal of Hydrometeorology, 4(1), pp. 1119-1133.

15. Freiwan, M., Cigizoglu, H.K., 2005, Prediction of total monthly rainfall in Jordan using feed forward back propagation method, Fresenius Environmental Bulletin, 14(2), pp. 142-151.

16. Chiang, Y.-M., Chang, F. J., Jou, B. J. D., Lin, P. F., 2007, Dynamic ANN for precipitation estimation and forecasting from radar observations, Journal of Hydrology, 334(1-2), pp. 250-261.

17. Nkuna, T.R., Odiyo, J.O., 2011, Filling of missing rainfall data in Luvuvhu River Catchment using artificial neural networks, Physics and Chemistry Earth, 36(1), pp. 830-835.

18. Mwale, F.D., Adeloye, A.J., Rustum, R., 2012, Infilling of missing rainfall and streamflow data in the Shire River basin, Malawi - A self organizing map approach. Physics and Chemistry Earth, 50(52), pp. 34-43.

19. Nastos, P.T., Moustris, K.P., Larissi, I.K., Paliatsos, A.G., 2013, Rain intensity forecast using Artificial Neural Networks in Athens, Greece, Atmospheric Research, 119(1), pp. 153-160.

20. Jang, J.-S.R, 1993, ANFIS: Adaptive-Network-based Fuzzy Inference Systems, IEEE Trans. On Systems, Man, and Cybernetics, 23(1), pp. 665-685.

21. Enayatifar, R., Javedani Sadaei, H., Hanan Abdullah, A., Gani, A., 2013, Imperialist Competitive Algorithm Combined with Refined High-Order Weighted Fuzzy Time Series for Short Term Load Forecasting, Energy Conversion and Management, 76(1), pp. 1104-1116.

22. Mohandes, M., Rehman, S., Rahman, S.M., 2011, Estimation of wind speed profile using adaptive neurofuzzy inference system (ANFIS), Applied Energy, 88(11), pp. 4024-4032.

23. Ata, R., Kocyigit, Y., Kocyigit, Y., 2010, An adaptive neuro-fuzzy inference system approach for prediction of tip speed ratio in wind turbines, Expert Systems with Applications, 37(1), pp. 5454-5460.

24. Shamshirband, S., Anuar, N.B., Kiah, M.L.M., Patel, A., 2013, An appraisal and design of a multi-agent system based cooperative wireless intrusion detection computational intelligence technique, Engineering Applications of Artificial Intelligence, 26(9), pp. 2105-2127. 
25. Ghandoor, A., Samhouri, M., 2009, Electricity Consumption in the Industrial Sector of Jordan: Application of Multivariate Linear Regression and Adaptive Neuro-Fuzzy Techniques, Jordan Journal of Mechanical and Industrial Engineering, 3(1), pp. 69-76.

26. Singh, R., Kianthola, A., Singh, T.N, 2012, Estimation of elastic constant of rocks using an ANFIS approach, Applied Soft Computing, 12(1), pp. 40-45.

27. Petković, D., Issa, M., Pavlović, N.D., Pavlović, N.T., Zentner, L., 2012, Adaptive neuro-fuzzy estimation of conductive silicone rubber mechanical properties, Expert Systems with Applications, 39(1), pp. 9477-9482.

28. Petković, D., Ćojbašić, Ž., 2012, Adaptive neuro-fuzzy estimation of automatic nervous system parameters effect on heart rate variability, Neural Computing and Application, 21(8), pp. 2065-2070.

29. Kurnaz, S., Cetin, O., Kaynak, O., 2010, Adaptive neuro-fuzzy inference system based autonomous flight control of unmanned air vehicles, Expert Systems with Applications, 37(1), pp. 1229-1234.

30. Petković, D., Issa, M., Pavlović, N.D., Zentner, L., Ćojbašić, Ž., 2012, Adaptive neuro fuzzy controller for adaptive compliant robotic gripper, Expert Systems with Applications, 39(1), pp. 13295-13304.

31. Tian, L., Collins, C., 2005, Adaptive neuro-fuzzy control of a flexible manipulator, Mechatronics, 15(2), pp. 1305-1320.

32. Ekici, B.B., Aksoy, U.T., 2011, Prediction of building energy needs in early stage of design by using ANFIS, Expert Systems with Applications, 38(5), pp. 5352-5358.

33. Khajeh, A., Modarress, H., Rezaee, B., 2009, Application of adaptive neuro-fuzzy inference system for solubility prediction of carbon dioxide in polymers, Expert Systems with Applications, 36(3), pp. 5728-5732.

34. Inal, M., 2008. Determination of dielectric properties of insulator materials by means of ANFIS: A comparative study, Expert Systems with Applications, 195(1-3), pp. 34-43.

35. Lo, S.P., Lin, Y.Y., 2005, The prediction of wafer surface non-uniformity using FEM and ANFIS in the chemical mechanical polishing process, Journal of Materials Processing Technology, 168(2), pp. 250-257.

36. Gocic, M., Trajkovic, S., 2013. Analysis of precipitation and drought data in Serbia over the period 1980-2010. Journal of Hydrology, 494(4), pp. 32-42.

37. Gocic, M., Trajkovic, S., 2014a. Spatiotemporal characteristics of drought in Serbia, Journal of Hydrology, 510(5), pp. 110-123.

38. Gocic, M., Trajkovic, S., 2014b, Spatio-temporal patterns of precipitation in Serbia, Theoretical and Applied Climatology, 117(3), pp. 419-431.

39. Kendall, M. G., Stuart, A., 1968, The Advanced Theory of Statistics: Design and Analysis, and Timeseries, Charles Griffin \& Company Limited, London.

40. Gocic, M., Trajkovic, S., 2013, Analysis of changes in meteorological variables using Mann-Kendall and Sen's slope estimator statistical tests in Serbia, Global and Planetary Change, 100(5), pp. 172-182. 